\title{
Edoxaban in elderly patient with morbid obesity and atrial fibrillation: the role of plasma levels evaluation for selecting the appropriate dose
}

\author{
Vincenzo Russo ${ }^{1}$, Anna Rago ${ }^{1}$, Nunzia Laezza ${ }^{1}$, Pierpaolo Di Micco², Laura Giannetti ${ }^{1}$, Luigi Atripaldi ${ }^{3}$, \\ Antonio D'Onofrio ${ }^{4}$, Paolo Golino', Gerardo Nigro ${ }^{1}$ \\ ${ }^{1}$ Cardiology Unit, University of Campania "Luigi Vanvitelli", Monaldi Hospital, Naples; ${ }^{2}$ Division of Internal \\ Medicine, Buonconsiglio Fatebenefratelli Hospital, Naples; ${ }^{3}$ Chemical Biochemistry Unit, Monaldi Hospital, Naples; \\ ${ }^{4}$ Division of Cardiology, Monaldi Hospital, Naples, Italy
}

\begin{abstract}
We present the case of a 80 -year-old man with atrial fibrillation, morbid obesity (weight $123 \mathrm{~kg}$, height $167 \mathrm{~cm}$, BMI 44.1), high clearance of creatinine and pharmacological polytherapy, in which the serial determinations of edoxaban plasma levels help us to choose the appropriate dose.
\end{abstract}

Correspondence: Vincenzo Russo, Cardiology Unit, University of Campania "Luigi Vanvitelli", Monaldi Hospital, Via Leonardo Bianchi 1, 80131 Naples, Italy.

Tel. +39.081.7062355.

E-mail: v.p.russo@libero.it

Contributions: All the authors made a substantive intellectual contribution. All the authors have read and approved the final version of the manuscript and agreed to be accountable for all aspects of the work.

Conflict of interest: The authors declare no conflict of interest

Funding: This research received no external funding.

Consent for publication: The manuscript does not contain any individual person's data in any form.

Acknowledgments: We gratefully thanks the nursing staff of Cardiology Unit Vanvitelli - Monaldi Hospital for the blood samples collection.

Key words: atrial fibrillation; obesity; non-vitamin k oral anticoagulant; plasma levels; edoxaban; elderly.

Received for publication: 1 January 2020.

Accepted for publication: 4 February 2020.

${ }^{\circ}$ Copyright: the Author(s), 2020

Licensee PAGEPress, Italy

Monaldi Archives for Chest Disease 2020; 90:1224

doi: 10.4081/monaldi.2020.1224

This article is distributed under the terms of the Creative Commons Attribution Noncommercial License (by-nc 4.0) which permits any noncommercial use, distribution, and reproduction in any medium, provided the original author(s) and source are credited.

\section{Introduction}

Obesity and atrial fibrillation (AF) are major risk factors for ischemic stroke [1]. The increased risk of cerebrovascular events in obese patients may be not only related to the accompanying comorbidities, but it may also be explained by a low-grade chronic inflammation, which is associated with a prothrombotic/procoagulant state [2]. In obese patients the glomerular filtration rate (GFR) and renal plasma flow (RPF) usually exceeded the control value by 51 and $31 \%$, respectively. Consequently, the filtration fraction may increase, enhancing the renal clearance of oral anticoagulants (OACs) [3]. For this reason, obese patients require greater doses of vitamin $\mathrm{K}$ oral anticoagulants (VKAs) and longer lead-in periods may be necessary for achieving therapeutic INR values [4]. Non-vitamin K oral anticoagulants (NOACs) should be preferred over VKAs for long-term stroke prevention in patients with non-valvular AF, according to the better clinical performance showed both in clinical trial [5-8] and in real life setting [9-13]. However, based on the lack of clinical data about the efficacy and safety of NOACs in morbidly obese patients, both the International Society on Thrombosis and Hemostasis (ISTH) and the NOACs summary of product characteristics do not recommend the use of NOACs in patients with a body mass index (BMI) $>40$ $\mathrm{kg} / \mathrm{m}^{2}$ or a weight $>120 \mathrm{~kg}$, unless drug specific peak or trough levels fall within the usual on therapy range [14]. We report a case of an elderly AF patient with morbid obesity, in which the serial determinations of NOAC plasma levels help us to choose the appropriate dose.

\section{Case Report}

An 80-year-old man with hypertensive cardiomyopathy, morbid obesity (weight $123 \mathrm{~kg}$, height $167 \mathrm{~cm}$, BMI 44.1), diabetes mellitus, dyslipidemia, chronic obstructive pulmonary disease, severe sleep apnea syndrome, peripheral artery disease of the lower limbs and paroxysmal atrial fibrillation was admitted to our department for arrhythmogenic evaluation. The mean blood pressure (BP) was $135 / 85 \mathrm{mmHg}$ over the last two weeks and the glycated hemoglobin (HbAlc) was 6.7\%. Trans-thoracic echocardiography showed hypertensive cardiomyopathy with an ejection fraction (EF), calculated by the Simpson's biplane method, of $55 \%$, mild mitral and aortic regurgitation.

The medical treatment included Olmersartan $40 \mathrm{mg}$ once daily (OD); Amlodipine 10 mg OD, Doxazosin 4 mg OD; Amiodaron 
$200 \mathrm{mg}$ OD, Metformin $1000 \mathrm{mg}$ three times daily, Furosemide 25 $\mathrm{mg}$ OD; Atorvastatin $80 \mathrm{mg}$ OD; Ezetimibe $10 \mathrm{mg}$ OD, Acetylsalicylic Acid $100 \mathrm{mg}$ OD.

For the high thromboembolic risk profile (CHA2DS2-VASc Score: 5), the patient was on anticoagulation therapy with Warfarin $5 \mathrm{mg}$ OD; however, he did not achieve at least $60 \%$ of the time in therapeutic range (INR Target 2-3), assessed thought the Rosendaal method (INR value range: 1.7-3.9). The serum creatinine level was $0.9 \mathrm{mg} / \mathrm{dl}$ and the estimated glomerular filtration rate, assessed by the Cockcroft-Gault equation, was $113.9 \mathrm{ml} / \mathrm{min} / 1.73 \mathrm{~m} 2$. We switched the therapy from warfarin to edoxaban and we choose the dosage of $30 \mathrm{mg}$ OD for the temporary concomitant use of acetylsalicylic acid $100 \mathrm{mg} \mathrm{OD}$, due to recent angioplasty with stenting for lower extremity artery disease.

We performed serial determinations of edoxaban plasma concentration. The edoxaban plasma level was detected by chromogenic anti-factor Xa assay according to the manufacturer's recommendations. The expected range of plasma levels at peak and through for standard was $91-321 \mathrm{dose} \mathrm{ng} / \mathrm{mL}$ and $31-230 \mathrm{ng} / \mathrm{mL}$, respectively. The clinical biochemistry laboratory of our institution has implemented and maintains a quality management system which fulfils the requirements of the standard ISO 9001:2008 (registration number: IT-74072).

The edoxaban plasma level at peak ( 2 hours after first intake) was $165 \mathrm{ng} / \mathrm{ml}$, at $4^{\text {th }}, 6^{\text {th }}$ and $24^{\text {th }}$ hour (at trough) was $151 \mathrm{ng} / \mathrm{ml}, 129$ $\mathrm{ng} / \mathrm{ml}$ and $2.2 \mathrm{ng} / \mathrm{ml}$, respectively (Figure 1). Given the low edoxaban plasma level at trough, we increased the dosage of edoxaban from 30 to $60 \mathrm{mg}$ OD and we performed the serial determinations of edoxaban plasma concentration, according the previously used protocol. The edoxaban plasma level at peak ( 2 hours after first intake) was 343 $\mathrm{ng} / \mathrm{ml}$, at $4^{\text {th }}, 6^{\text {th }}$ and $24^{\text {th }}$ hour (at trough) was $324 \mathrm{ng} / \mathrm{ml}, 285 \mathrm{ng} / \mathrm{ml}$ and $32.8 \mathrm{ng} / \mathrm{ml}$, respectively (Figure 1).

At the three months follow-up, the hemoglobin value and the estimated glomerular filtration rate, assessed by the Cockcroft-Gault equation, were stable; the patient did not report any side effect. The adherence to the edoxaban therapy was $98 \%$.

\section{Discussion}

The optimal anticoagulant treatment for stroke prevention in obese patients with atrial fibrillation is still a matter of debate. On one hand, VKAs required an increased starting dosage and more

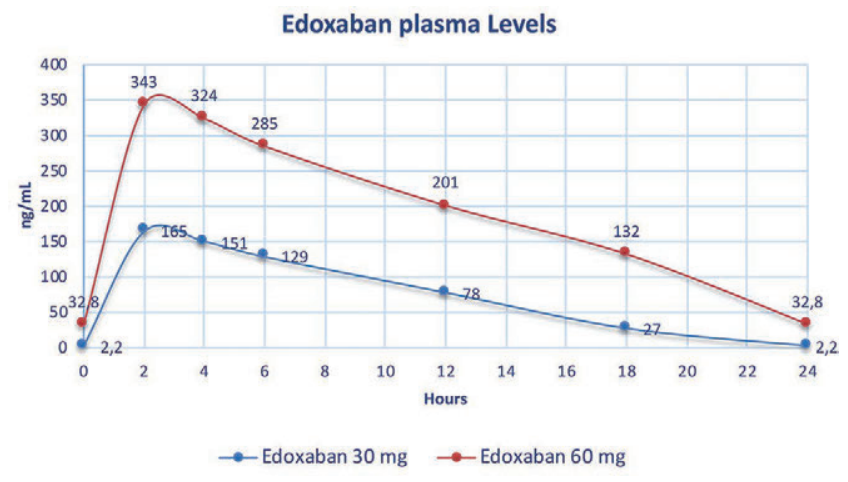

Figure 1. Edoxaban plasma level at peak and at trough. time for achieving the international normalized ratio (INR) values within the therapeutic range [15]; on the other hand, no large randomized controlled trial has specifically investigated the efficacy and safety of NOACs in the obese population and the current guidelines recommends avoiding NOACs in morbidly obese patients (BMI $>40 \mathrm{~kg} / \mathrm{m} 2$ or weight $>120 \mathrm{~kg}$ ) [14]. Several recent studies (weight-based post-hoc analyses and retrospective cohort studies) investigated the clinical performance of NOACs in morbidly obese patients with AF [16-18].

Despite the recommendations of the ISTH guidelines, we switched the oral anticoagulation therapy from warfarin to edoxaban on the basis of our clinical experience that demonstrated a good clinical performance of edoxaban among elderly patients with AF [19]; moreover, a recent post- hoc analysis of ENGAGE AF TIMI 48 study showed that the efficacy and safety profiles of edoxaban $v$ s warfarin were similar across BMI categories ranging from 18.5 to $>40$ [20].

The reduced edoxaban dose (30 mg OD) was empirically used for minimizing the bleeding risk related to the concomitant acetylsalicylic acid therapy; to date there are scarce evidence to support a specific antithrombotic regimen in patients with lower extremity artery disease and an indication for oral anticoagulation. The duration of combined therapy should be as limited as possible, depending on the clinical indication and bleeding risk.

We decide to evaluate the edoxaban serum level at peak and trough because the reduced dose was empirically prescribed, not according to the SmPC criteria for dose reduction, and because our patient showed high estimated clearance of creatinine ( $>95 \mathrm{~mL} / \mathrm{min})$; this condition is been related to a decreased efficacy of edoxaban compared with warfarin in the ENGAGE AF TIMI 48 study.

The evaluation of edoxaban serum level at peak and trough time demonstrated a low therapeutic drug levels of edoxaban when 30 mg OD was used, while the correct therapeutic drug levels were reached when edoxaban $60 \mathrm{mg}$ was used. The use of plasma level monitoring for NOAC dose-adjustment is discouraged for the vast majority of patients due to the lack of outcome data to support such an approach; however, in rare cases of potentially substantial drugdrug interactions, or in special population in which the use of NOACs is still debated, or in case of not deferrable cardiac or noncardiac interventional or surgical procedures, this approach may be considered.

\section{Conclusions}

The present clinical case suggests a possible role of edoxaban plasma levels evaluation for selecting the appropriate dose in elderly patient with morbid obesity and atrial fibrillation and suggests the edoxaban therapy could be as a valid alterative to VKA therapy in this special population.

\section{References}

1. Strazzullo P, D'Elia L, Cairella G, et al. Excess body weight and incidence of stroke: meta-analysis of prospective studies with 2 million participants. Stroke 2010;41:e418-26.

2. Sonnenberg G, Krakower G, Kissebah A. A novel pathway to the manifestations of metabolic syndrome. Obes Res 2004; 12:180-6.

3. Chagnac A, Weinstein T, Korzets A, et al. Glomerular 
hemodynamics in severe obesity. Am J Physiol Renal Physiol 2000;278:F817-22.

4. Wallace JL, Reaves AB, Tolley EA, et al. Comparison of initial warfarin response in obese patients versus non-obese patients. J Thromb Thrombolysis 2013;36:96-101.

5. Connolly SJ, Ezekowitz MD, Yusuf S, et al. Dabigatran versus warfarin in patients with atrial fibrillation. N Engl J Med 2009;361:1139-51.

6. Patel MR, Mahaffey KW, Garg J, et al. Rivaroxaban versus warfarin in nonvalvular atrial fibrillation. $\mathrm{N}$ Engl J Med 2011;365:883-91.

7. Granger CB, Alexander JH, McMurray JJ, et al. Apixaban versus warfarinin patients with atrial fibrillation. N Engl J Med 2011;365:981-92.

8. Giugliano RP, Ruff CT, Braunwald E, et al. Edoxaban versus warfarin in patients with atrial fibrillation. N Engl J Med 2013;369:2093-104.

9. Russo V, Bianchi V, Cavallaro C, et al. Efficacy and safety of dabigatran in a "real-life" population at high thromboembolic and hemorrhagic risk: data from Monaldi Care registry. Eur Rev Med Pharmacol Sci 2015;19:3961-7.

10. Russo V, Rago A, Proietti R, et al. Efficacy and safety of the target-specific oral anticoagulants for stroke prevention in atrial fibrillation: the real-life evidence. Ther Adv Drug Saf 2017;8:67-75

11. Russo V, Attena E, Di Maio M, et al. Clinical profile of direct oral anticoagulants versus vitamin $\mathrm{K}$ anticoagulants in octogenarians with atrial fibrillation: a multicentre propensity score matched real-world cohort study. J Thromb Thrombolysis 2020;49:42-53.

12. Russo V, Carbone A, Rago A, et al. Direct oral anticoagulants in octogenarians with atrial fibrillation: it's never too late. J Cardiovasc Pharmacol 2019;73:207-14.
13. Verdecchia P, D'Onofrio A, Russo V, et al. Persistence on apixaban in atrial fibrillation patients: a retrospective multicentre study. J Cardiovasc Med (Hagerstown) 2019;20: 66-73.

14. Martin K, Beyer-Westendorf J, Davidson BL, et al. Use of the direct oral anticoagulants in obese patients: guidance from the SSC of the ISTH. J Thromb Haemost 2016;14:1308-13.

15. Self TH, Wallace JL, Sakaan S, Sands CW. Effect of body weight on dose of vitamin K antagonists. South Med J 2015;108:637-43.

16. Kido K, Ngorsuraches S. Comparing the efficacy and safety of direct oral anticoagulants with warfarin in the morbidly obese population with atrial fibrillation. Ann Pharmacother 2019;53:165-70.

17. Sandhu RK, Ezekowitz J, Andersson U, et al. The 'obesity paradox' in atrial fibrillation: observations from the ARISTOTLE (Apixaban for Reduction in Stroke and Other Thromboembolic Events in Atrial Fibrillation) trial. Eur Heart J 20167;37:2869-78.

18. Upreti VV, Wang J, Barrett YC, et al. Effect of extremes of body weight on the pharmacokinetics, pharmacodynamics, safety and tolerability of apixaban in healthy subjects. Br J Clin Pharmacol 2013;76:908-16.

19. Russo V, Attena E, Mazzone C, et al. Real-life performance of edoxaban in elderly patients with atrial fibrillation: a multicenter propensity score-matched cohort study. Clin Ther 2019;41:1598-604.

20. Boriani G, Ruff CT, Kuder JF, et al. Relationship between body mass index and outcomes in patients with atrial fibrillation treated with edoxaban or warfarin in the ENGAGE AF-TIMI 48 trial. Eur Heart J 2019;40:1541-50. 